\title{
PANORAMA DA RECICLAGEM NO BRASIL: PERSPECTIVAS SOCIOECONÔMICAS E AMBIENTAIS
}

\author{
Laís dos Santos Pacheco ${ }^{1}$ \\ Daniella Aurora do Nascimento ${ }^{2}$ \\ Kerley dos Santos Alves ${ }^{3}$ \\ Vera Lúcia de Miranda Guarda ${ }^{4}$
}

\begin{abstract}
RESUMO
Desde a aprovação da Política Nacional de Resíduos Sólidos (PNRS), em 2010, esperava-se que o Brasil obtivesse avanços significativos em relação à gestão integrada de resíduos. A PNRS prevê ações que englobam a geração, o tratamento e a disposição final destes, sendo parte do processo a implementação da reciclagem no país. Nesse contexto, este trabalho teve como objetivo analisar o panorama da reciclagem no Brasil sob enfoque socioeconômico e ambiental. Para responder ao problema de pesquisa, foi realizado um estudo bibliográfico em bases de dados nacionais. Após uma seleção inicial, o total de 25 artigos, publicados entre 2010 e 2020, foi analisado mais detalhadamente. Constatou-se que a maioria das publicações analisadas se concentrou no eixo Social, além de grande parte expor as maiores dificuldades enfrentadas nacionalmente para a implementação das diretrizes dispostas na PNRS. Apesar dos inúmeros benefícios que pode gerar nos âmbitos social, econômico e ambiental, a reciclagem ainda representa uma atividade com potencial não explorado no Brasil, enfrentando diversos gargalos para sua completa implementação. Por isso, reconhecer os principais atores que atuam na cadeia da reciclagem, investir nas cooperativas, incentivar a educação ambiental da população e fazer valer as orientações da PNRS são ações capazes de impulsionar o país para o caminho de uma gestão mais integrada e sustentável.
\end{abstract}

\section{PALAVRAS-CHAVE}

Reciclagem; Resíduos sólidos; Brasil; Políticas Públicas.

\footnotetext{
1 Mestranda do Programa de Pós-Graduação em Sustentabilidade Socioeconômica Ambiental da Universidade Federal de Ouro Preto (PPGSSA/UFOP). E-mail: laisdspacheco@gmail.com

${ }^{2}$ Graduanda em Engenharia Ambiental pela Universidade Federal de Ouro Preto (UFOP). E-mail: daniellanascimento07@gmail.com

3 Docente do Programa de Pós-Graduação em Sustentabilidade Socioeconômica Ambiental da Universidade Federal de Ouro Preto (PPGSSA/UFOP). E-mail: kerleysantos@yahoo.com.br

4 Docente do Programa de Pós-Graduação em Sustentabilidade Socioeconômica Ambiental da Universidade Federal de Ouro Preto (PPGSSA/UFOP). E-mail: veraguarda2@gmail.com
}

Revista Gestão e Sustentabilidade Ambiental., v. 10, n. 4, p. 33-53, dez. 2021. 


\begin{abstract}
Since the approval of the National Solid Waste Policy, in 2010, it was expected that Brazil would make significant progress related to integrated waste management. The National Waste Policy predicts actions that encompass generation, treatment and final disposal of these, being part of the recycling implementation process in the country. In this context, this work aimed to analyze the scenery of recycling in Brazil from a socioeconomic and environmental perspective. To answer the problem of the research, a bibliometric study was carried out on national databases. After an initial selection, the total of 25 articles, published between 2010 and 2020, was analyzed in more detail. It was found that the majority of publications analyzed was centered on social axis. In addition, many articles expose difficulties faced nationally on the implementation of National Solid Waste Policy guidelines. Besides many benefits that can be generated on social, economic and environmental axis, the activity of recycling still represents a non-explored potential in Brazil, facing several difficulties on its implementation. Therefore, recognizing the main agents in the recycling business, investing in cooperatives, encouraging environmental education and applying National Solid Waste Policy orientations are potential actions for pushing the country towards a more integrated and sustainable management.
\end{abstract}

KEYWORDS

Recycling; Solid Waste; Brazil; Public Policy. 


\section{INTRODUÇÃO}

Nos dias de hoje, uma das principais problemáticas ambientais está relacionada à gestão de resíduos sólidos urbanos. Altas taxas de crescimento demográfico, aumento da produção industrial e padrões de consumo cada vez mais elevados são alguns dos fatores que estão ligados à crescente geração de resíduos e ao agravamento dessa questão nos últimos anos (REIS; PONTES, 2019).

Sendo assim, a sociedade atual se encontra diante do desafio de encontrar soluções alternativas para a problemática dos resíduos, principalmente aquelas baseadas nos pilares do desenvolvimento sustentável. Soluções estas que englobem desde as primeiras etapas de produção, com a extração de recursos naturais, as formas de consumo, até a disposição final dos resíduos (CELERI; CORTEZ, 2017). O gerenciamento dos resíduos é complexo e precisa estar articulado a diferentes agentes, como a população, os catadores, os poderes públicos e privados, entre outros. Dessa forma, diversas estratégias devem estar interligadas para uma melhor gestão dos Resíduos Sólidos Urbanos (RSU). E é nesse contexto que a reciclagem vem ganhando cada vez mais espaço neste debate (GARCIA et al., 2015).

Reciclar significa transformar materiais que aparentemente não teriam mais uso em matéria-prima para produtos novos. Segundo a Política Nacional de Resíduos Sólidos (PNRS), a reciclagem pode ser definida como:

Processo de transformação dos resíduos sólidos que envolve a alteração de suas propriedades físicas, físico-químicas ou biológicas, com vistas à transformação em insumos ou novos produtos, observadas as condições e os padrões estabelecidos pelos órgãos competentes do SISNAMA (Sistema Nacional do Meio Ambiente) e, se couber, do SNVS (Sistema Nacional de Vigilância Sanitária) e do SUASA (Sistema Unificado de Atenção à Sanidade Agropecuária) (BRASIL, LEI № 12.305/2010, art. 3ํ, inciso XIV).

Em 2010, após 19 anos de tramitação, foi aprovado o projeto da Política Nacional dos Resíduos Sólidos (PNRS) no país, instituída pela Lei ํㅜ 12.305, de 02 de agosto de 2010. Ela engloba orientações para uma gestão integrada e sustentável dos resíduos sólidos (SILVA; ROSAS; OLIVEIRA, 2018). Conforme suas diretrizes, o país deveria ter até 2020 as bases necessárias para tratar de forma eficiente a questão dos resíduos, do ponto de vista social, econômico e ambiental. A PNRS estabeleceu que 
os municípios elaborassem e colocassem em prática um plano de gerenciamento de resíduos sólidos até 2014. Este deveria conter metas de incentivo à reciclagem, redução da geração de resíduos, plano para extinguir os lixões, entre outras diretrizes. Além disso, introduziu o conceito da logística reversa, estipulando a responsabilidade compartilhada pelo ciclo de vida dos produtos para a sociedade, poder público e privado (THODE FILHO et al., 2015).

Apesar das iniciativas, o país ainda não cumpriu todas essas determinações, estando muito aquém do esperado. Entretanto, levando em consideração a importância da reciclagem, esta, como investimento, poderia resultar em um amplo desenvolvimento para o Brasil (GRISA; CAPANEMA, 2018). Para tal, é de extrema importância entender seu contexto histórico e sua relevância atual (DEUS; BATTISTELLE; SILVA, 2015). Dessa forma, este estudo tem como objetivo analisar o panorama da reciclagem no Brasil em uma abordagem socioeconômica e ambiental, com base em publicações dos últimos dez anos.

\section{METODOLOGIA}

Para alcançar o objetivo proposto, realizou-se uma pesquisa bibliográfica de natureza exploratória e de caráter descritivo (VERGARA; PECI, 2003). Esse tipo de pesquisa consiste em revisar a literatura existente sobre as principais teorias relacionadas ao tema proposto, podendo ser realizado em livros, periódicos, artigos de jornais, sites da internet entre outras fontes (PIZZANI et al., 2012). Para esta pesquisa, foi utilizada literatura técnico-científica. Além disso, a metodologia foi baseada em uma abordagem quali-quantitativa, lançando-se mão de técnicas relacionadas à pesquisa bibliográfica.

O levantamento bibliográfico foi realizado entre os meses de março e junho de 2020. Assim, a leitura foi a principal técnica empregada, de modo que a análise de conteúdo dos artigos foi realizada para explorar os temas e principais resultados dos trabalhos analisados. Na primeira etapa de pesquisa, selecionaram-se as bases de dados a serem utilizadas, como o Portal de Periódicos da Coordenação de Aperfeiçoamento de Pessoal de Nível Superior (CAPES) e o Google Acadêmico. 


\section{¿unisul}

Para a busca, foi utilizada a combinação dos descritores "Reciclagem", "Perfil", "Brasil" e "Perfil da reciclagem", buscando objetivar o tema. Além dos descritores iniciais, optou-se por analisar trabalhos publicados entre os períodos de 2010 a 2020, uma vez que os trabalhos realizados anteriormente a esse período ainda não consideram a PNRS, além de optar por reunir as informações mais recentes sobre o tema, facilitando a avaliação do panorama atual da reciclagem no país.

Utilizando a plataforma CAPES, obteve-se o retorno de 42 trabalhos em que ao menos o título possuía informações relevantes ao tema. E, ao utilizar a plataforma do Google Acadêmico, foi possível tomar conhecimento de 19 trabalhos inicialmente relevantes, totalizando, assim, 59 trabalhos. Estes foram analisados em diversas etapas.

A leitura inicial do resumo, objetivo e introdução dos 59 trabalhos selecionados permitiu classificar 25 deles, que continham informações relacionadas a pelo menos um dos cinco eixos propostos (Gestão, Definição e Histórico; Ambiental; Econômico; Social; e PNRS), eixos estes que foram escolhidos com o intuito de dar um enfoque interdisciplinar à pesquisa e alinhá-la, também, aos principais pilares do desenvolvimento sustentável. Os artigos que não se enquadraram em nenhum desses eixos foram descartados, conforme a Figura 1. 


\section{GESTÃO \& SUSTENTABILIDADE}

AMBIENTAL

\section{¿Unisul}

Figura 1 - Fluxograma representando os métodos utilizados para seleção dos trabalhos analisados.

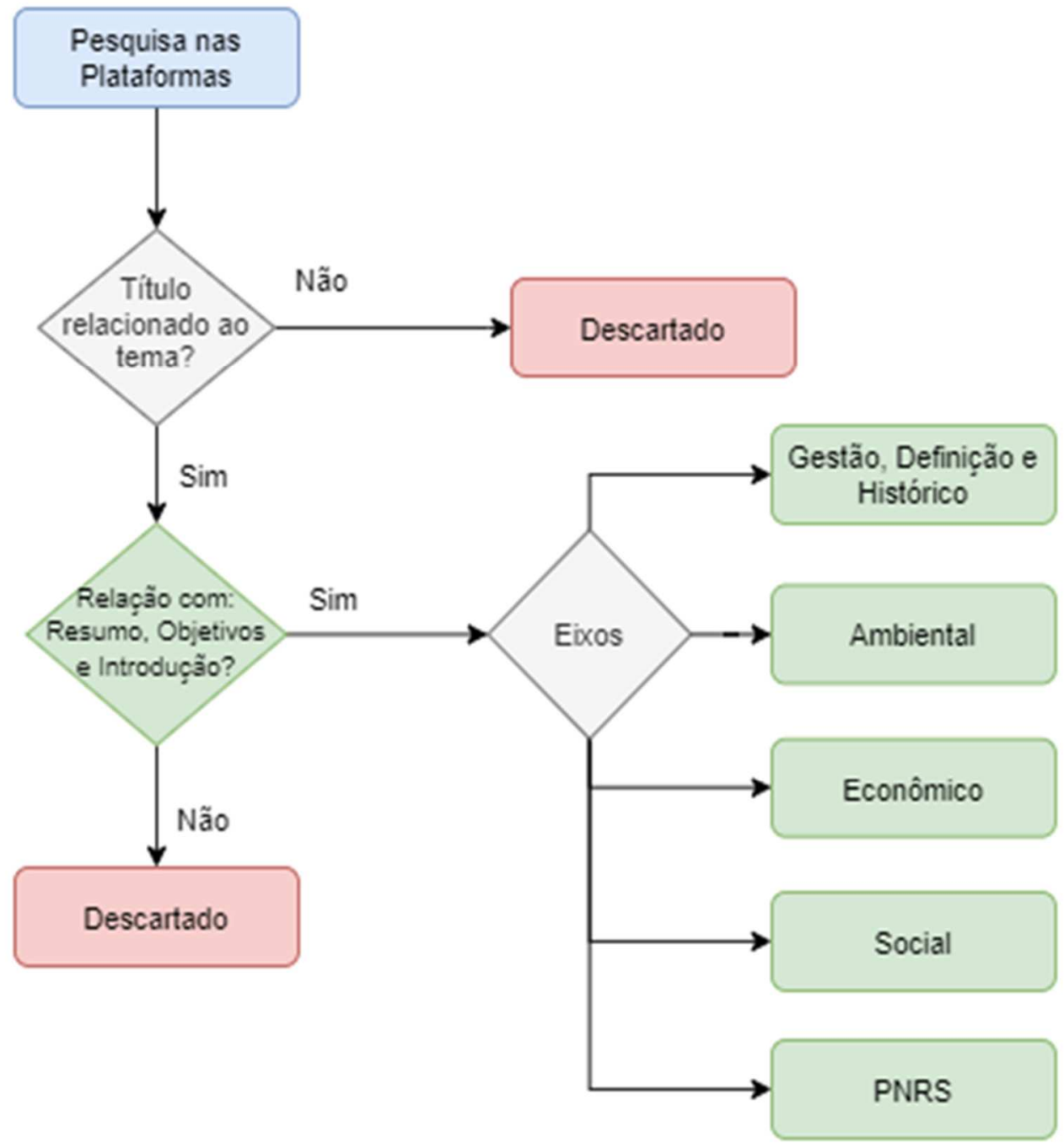

A partir disso, utilizando o software Microsoft Office Excelß, houve a elaboração de uma planilha com as seguintes informações: título, autoria, ano de publicação, plataforma de pesquisa e eixo de trabalho, permitindo, portanto, uma melhor organização dos trabalhos. Uma leitura detalhada dos 25 trabalhos classificados foi realizada de forma a identificar mais precisamente com quais eixos cada trabalho estava mais relacionado. 


\section{RESULTADOS E DISCUSSÃO}

\subsection{AVALIAÇÃO DOS ARTIGOS SELECIONADOS POR ANO E EIXO CLASSIFICATÓRIO}

Os vinte e cinco trabalhos selecionados estão apresentados por ano de publicação no gráfico da Figura 2. É notável a quantidade de trabalhos publicados no ano de 2015. O fato pode ser explicado pelo prazo estipulado pela Política Nacional de Resíduos Sólidos (PNRS) para que os municípios elaborassem e colocassem em prática uma estratégia de gerenciamento de resíduos sólidos, com metas de incentivo à reciclagem e plano para extinguir os lixões até 2014.

Figura 2 - Número de publicações referentes ao tema da reciclagem no Brasil por ano, entre 2010 e 2020. Dados de busca realizada entre março e junho de 2020 no Portal de Periódicos da CAPES e no Google Acadêmico.

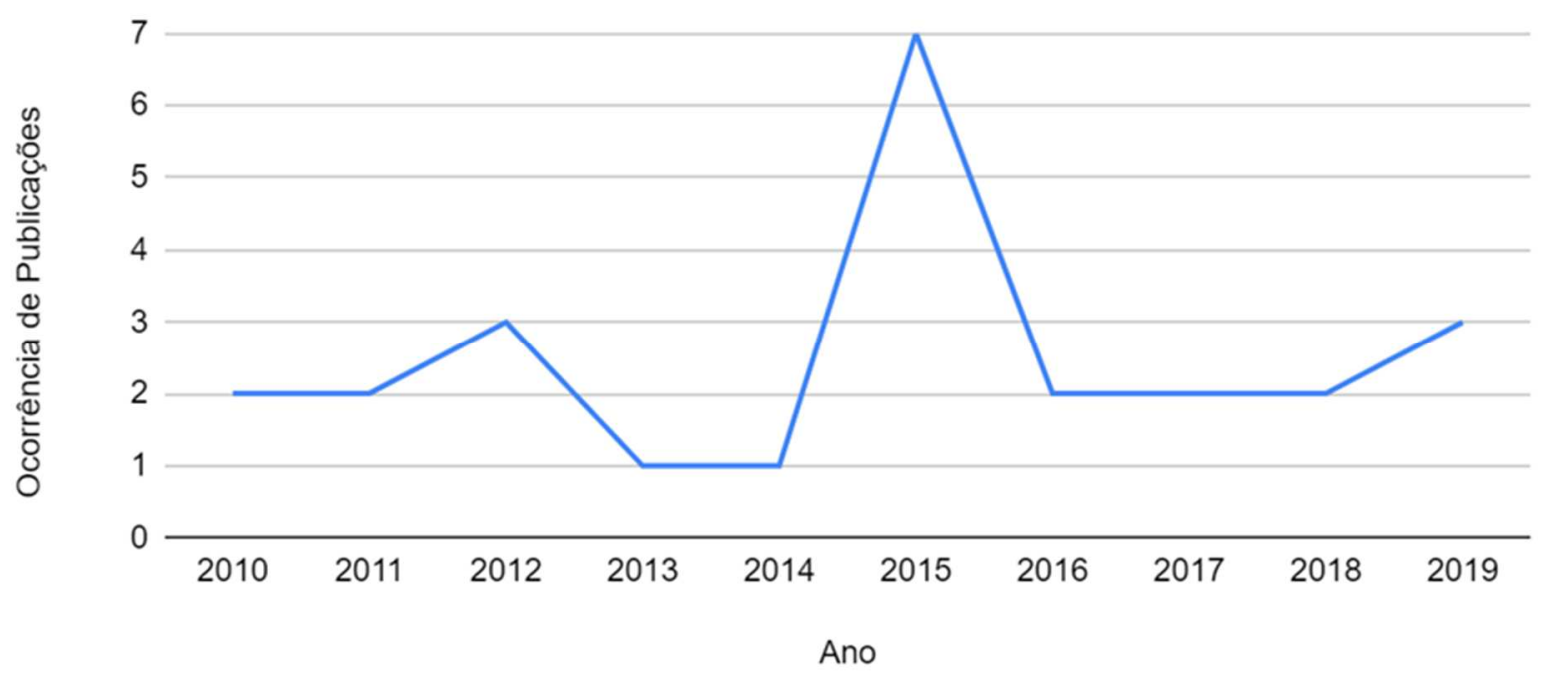

Em relação à quantidade de trabalhos por eixo (Gestão, Histórico e Definição; Ambiental; Econômico; Social; PNRS), observou-se que o Social foi o grupo com o maior número de representantes, enquanto os eixos Ambiental e Econômico foram minoria. Foi possível notar também que os artigos não se mantiveram em apenas um eixo temático, abordando mais de um ou até mesmo englobando todos eles. Assim, 


\section{sunisul उrims}

obteve-se: 10 artigos no eixo Social; 5 em Gestão, Histórico e Definição; 1 em PNRS; 0 apenas no eixo Ambiental; 0 somente no eixo Econômico; 2 abrangendo os eixos Ambiental e Social em conjunto; 1 em Econômico e Ambiental; 4 em PNRS e também em Gestão, Histórico e Definição; 1 em PNRS e Econômico; e 1 englobando todos os eixos. Totalizando, assim, os 25 artigos analisados (Figura 3).

Figura 3 - Diagrama de Venn indicando o número de artigos por eixo temático, tanto aqueles que se enquadraram em apenas um dos eixos quanto os que abrangeram mais de uma área, totalizando 25 trabalhos selecionados sobre a Reciclagem no Brasil, entre 2010 e 2020.

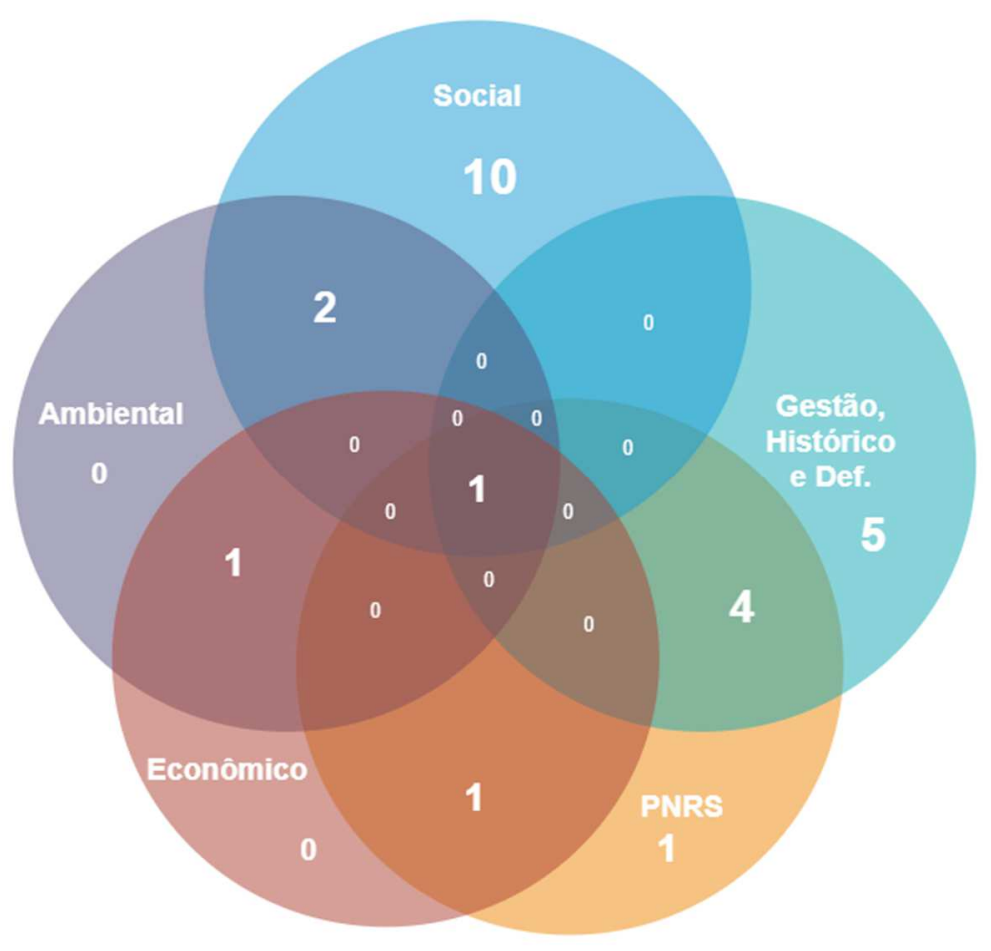

A análise dos artigos por ano de publicação permitiu a constatação de que houve a predominância de trabalhos do eixo social entre os anos 2010 a 2014. Em 2015, o tema da PNRS começa a ser mais retratado. Já entre 2016 a 2020, a temática envolvendo Gestão, Histórico e Definição se destaca, conforme apresentado na Figura 4. 


\section{¿unisul}

Figura 4 - Relação entre número de artigos avaliados em cada eixo temático por ano de publicação, entre 2010 e 2020. Dados referentes à busca realizada entre março e junho de 2020 no Portal de Periódicos da CAPES e no Google Acadêmico sobre a Reciclagem no Brasil.

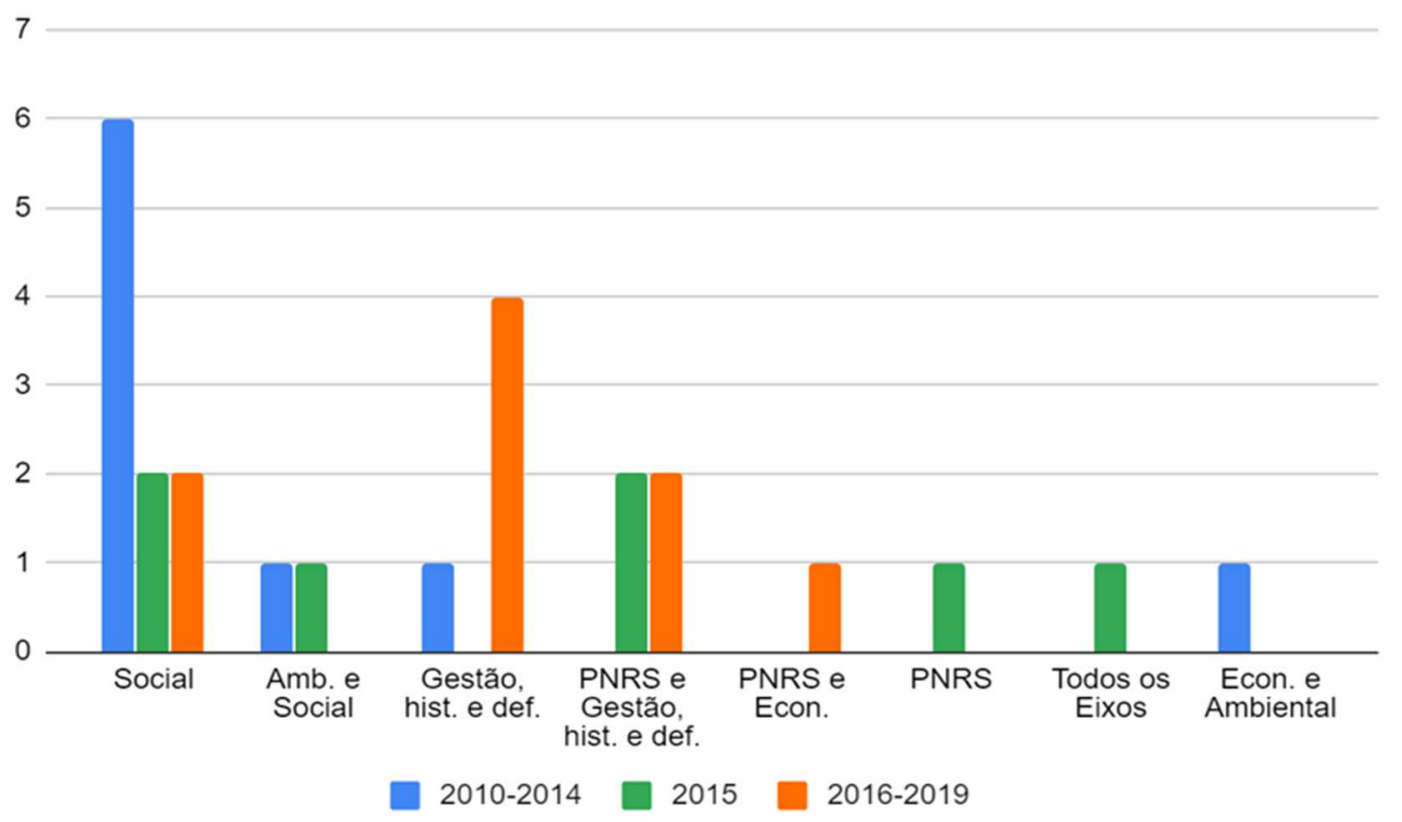

A predominância de artigos do eixo social entre 2010 e 2014 pode ser parcialmente explicada pelo cenário do país no momento, marcado pelo prosseguimento de políticas públicas de auxílios sociais. Nesse contexto, é possível citar a criação da Bolsa Reciclagem, em 2011, criada com o intuito de auxiliar financeiramente os catadores pelos serviços ambientais prestados (SILVEIRA; SOUSA; TEIXEIRA, 2019). Além disso, a própria discussão da extinção dos lixões carrega toda a questão dos catadores, que por anos viviam às margens destes, trabalhando em condições insalubres. Esta situação trouxe à tona a necessidade do poder público oferecer o suporte necessário para esses trabalhadores após sua saída desse ambiente, propiciando alternativas para geração de renda e condições mais dignas de trabalho, como a criação de programas de coleta seletiva e o apoio à criação de cooperativas de reciclagem, por exemplo. 
A partir de 2015, a maioria das pesquisas começa a abordar a PNRS. Este é o ano em que a Política Nacional de Resíduos Sólidos entra no seu quinto aniversário de aprovação, um ano após o prazo estipulado para o cumprimento dos planos de gerenciamento de resíduos no país. O ano de 2015 destacou-se não apenas pela quantidade de artigos, mas também pela heterogeneidade dos mesmos, pois os artigos analisados foram classificados em todos os eixos que foram demarcados nesse trabalho.

No período de 2016 a 2020 observou-se que os temas começaram a sofrer variações. Uma maior concentração de artigos envolvendo o eixo classificatório de Gestão, Histórico e Definição, seja isoladamente ou em conjunto com o eixo da PNRS, se destaca. Os temas variavam desde o que vem sendo feito pela gestão pública em relação à reciclagem, bem como os caminhos percorridos pela reciclagem nos últimos anos e como se estabeleceu a atividade no país. É provável que essa necessidade de criar panoramas esteja relacionada à baixa aderência dos mais diversos municípios brasileiros a uma gestão adequada dos resíduos, sendo que uma visão geral desse cenário representa uma ferramenta importante para sinalizar as melhorias que ainda precisam ser feitas. Artigos do eixo Social em combinação com os eixos PNRS e Econômico também foram classificados nesse período (Figura 4).

\subsection{POLÍTICA NACIONAL DE RESÍDUOS SÓLIDOS (PNRS)}

A PNRS estabeleceu uma nova ordem de prioridade para o gerenciamento dos resíduos: não-geração; redução; reutilização; reciclagem; tratamento; e disposição final ambientalmente adequada. Além disso, a PNRS estabelece a responsabilidade compartilhada pelo ciclo de vida dos produtos para a sociedade, poder público e privado (THODE FILHO, 2015). Assim, apesar de alguns dos princípios para uma gestão adequada dependerem da conscientização da população (o que pode ser estimulado através de programas de educação ambiental, ponto que também é incentivado pela política) (OLIVEIRA; GALVÃO, 2016), para que a sociedade possa fazer sua parte, os poderes público e privado precisam, antes, cumprir suas responsabilidades e oferecer condições básicas de logística e organização. Afinal, uma gestão sustentável é 
construída com a participação de todos, porém, para que isso se concretize, alguns agentes têm papéis cruciais a cumprir.

A Política Nacional de Resíduos Sólidos também introduz o conceito da logística reversa, que se refere ao retorno dos produtos, após o consumo, ao setor privado, que será responsável por reaproveitar ou fazer a destinação final adequada do resíduo (SOUZA; MELO, 2020). Além disso, a PNRS preconiza que a reciclagem é um dos elementos fundamentais para garantir a efetividade de uma gestão adequada (OLIVEIRA; GALVÃO, 2016). Sendo assim, concebe formas de incluir os catadores nos planos de gerenciamento municipais e garantir um maior suporte para suas formas de organização.

\subsection{PANORAMA BRASILEIRO}

Segundo dados do Panorama dos Resíduos Sólidos no Brasil, produzido pela Associação Brasileira de Empresas de Limpeza Pública e Resíduos Especiais, a geração de resíduos estimada no ano de aprovação da PNRS (2010) era de 60.868,080 ton./ano (ABRELPE, 2010) e em 2018 era de 79.069,585 ton./ano (ABRELPE, 2018). Ou seja, houve um aumento de quase 19.000 toneladas.

Uma das expectativas era de que a implementação da PNRS resultasse em uma efetivação mais ampla da coleta seletiva, um serviço que contemplava apenas 17,87\% dos municípios em 2008, segundo dados da Pesquisa Nacional de Saneamento Básico (IBGE, 2008). Em 2018, o Diagnóstico do Manejo de Resíduos Sólidos apontou que $38,10 \%$ dos municípios contavam com o serviço (SNIS, 2018), mostrando um aumento muito incipiente desde a sua aprovação.

Em 2017, 59\% dos resíduos coletados no país foram destinados a aterros sanitários, enquanto $41 \%$ foram alocados em lixões ou aterros controlados - destinação considerada imprópria e irregular (REIS; PONTES, 2019).

Além disso, em 2010 apenas 13\% dos resíduos coletados tinham como destino final a reciclagem (IPEA, 2010). E em 2018 apenas 1,7\% do total de resíduos 
domiciliares e públicos coletados foram destinados a usinas de triagem (SNIS, 2018). Esses dados demonstram que o Brasil ainda tem muito a avançar no tocante à gestão de resíduos.

\subsection{A QUESTÃO SOCIAL DA RECICLAGEM}

No âmbito social, a reciclagem tem como protagonista a figura do catador de materiais recicláveis, reconhecido desde 2002 pela Classificação Brasileira de Ocupações. Silva et al. (2018) abordam a dificuldade de determinar o número oficial de catadores no Brasil. Isso ocorre principalmente devido ao preconceito social que ainda circunda a profissão. Entretanto, dados levantados pelo Movimento Nacional dos Catadores de Materiais Recicláveis - MNCR estimam que existam cerca de 800 mil catadores em atividade (MNCR, 2019).

Entender os aspectos que permeiam a vida dos principais agentes da reciclagem é de extrema importância, afinal, como sinaliza Oliveira (2010), a análise da dimensão social permite a criação de um quadro histórico mais detalhado que abrange os catadores, sendo possível observar os caminhos trilhados até a vulnerabilidade na qual se encontram hoje, principalmente na situação da pandemia de COVID-195.

O relatório de 2020 dos Objetivos de Desenvolvimento Sustentável destaca que a pandemia tem agravado situações de desigualdade, não afetando a todos do mesmo modo: os mais vulneráveis (mais pobres, idosos, mulheres, crianças, negros, indígenas, entre outros) sofrem as consequências da pandemia de forma mais severa (UN, 2020). Além disso, no contexto da gestão de resíduos, os trabalhadores do ramo da reciclagem encontram-se expostos à contaminação em diferentes níveis, da coleta à triagem dos materiais, que podem permanecer com o vírus na sua superfície por determinado período, representando um alto risco aos catadores (PUGLIESI; SANTIAGO; LEITE, 2020).

\footnotetext{
${ }^{5}$ A doença respiratória causada pelo novo coronavírus (SARS-CoV-2) foi classificada como pandemia pela Organização Mundial da Saúde (OMS) em 2020, após atingir grande parte da população de diferentes partes do mundo.
}

Revista Gestão e Sustentabilidade Ambiental., v. 10, n. 4, p. 33-53, dez. 2021. 
O ramo da reciclagem é marcado pela presença majoritária de mulheres negras, abrangendo um amplo espectro de idades (desde mais jovens a indivíduos mais idosos), com baixa escolaridade (a maioria dos catadores possui ensino fundamental incompleto), e que muitas vezes enxergam a catação como a única oportunidade disponível frente ao desemprego (um dos fatores mais frequentemente alegados como motivadores para o ingresso no ramo da reciclagem). Além disso, os catadores fazem parte de uma categoria marcada pela precariedade laboral, não só pela insegurança relacionada à instabilidade do vínculo empregatício, como também por suas condições de trabalho (ANDRADE; FERREIRA, 2011; BOURAHLI et al., 2011; SILVEIRA; SOUSA; TEIXEIRA, 2019; SOUZA; PAULA; SOUZA-PINTO, 2012).

A organização dos catadores em associações ou cooperativas resulta em inúmeros benefícios, sendo possível destacar: a ruptura com o tipo solitário de trabalho, propiciando a formação de uma rede capaz de promover o apoio mútuo, reivindicar de forma mais efetiva seus direitos e ainda ajudar a promover maior lucro com os materiais coletados; a retirada desses trabalhadores de ambientes como lixões, apresentandoIhes a cooperativa como um ambiente de trabalho mais seguro; contribui para recuperar a autoestima, a cidadania e a identidade dos catadores; melhora a sua condição socioeconômica; e ainda ajuda a diminuir a dependência dos intermediários da cadeia de reciclagem (BOURAHLI et al., 2011; ESTEVES, 2015; SILVA; FUGII; MARINI, 2015; SILVA, 2017).

Apesar de serem prestadores de um serviço tão valioso para a sociedade, esses trabalhadores ainda enfrentam diversas dificuldades, estando em uma situação de elevada vulnerabilidade social (RIBEIRO et al., 2014). Os catadores são os grandes responsáveis pela maior parte da atividade de reciclagem desenvolvida no país. Portanto, é necessário oferecer a estes trabalhadores maior valorização e melhores condições de trabalho, sejam elas salariais, de infraestrutura, segurança ou profissionalização (GRISA; CAPANEMA, 2018). 


\subsection{A QUESTÃO ECONÔMICA DA RECICLAGEM}

A reciclagem tem a capacidade de fazer com que o resíduo seja passível de valoração econômica. Apesar disso, o país ainda trata essa atividade como algo inviável economicamente, e talvez por isso os serviços de coleta seletiva ainda ocorram de maneira tão incipiente (SOUZA; CHAVES; ALVIM, 2015).

Souza, Chaves e Alvim (2015) abordam os diversos benefícios relacionados à reciclagem, mas também pontuam uma alta nos custos da coleta seletiva em relação à coleta tradicional. Dados do Compromisso Empresarial Para Reciclagem (CEMPRE) apontam que, em 2018, os custos com a coleta seletiva se mostraram 4,6 vezes mais altos em relação à coleta normal. Entretanto, os benefícios resultantes da atividade superam esses custos iniciais: o IPEA estimou em 2010 que, se os resíduos recicláveis dispostos em lixões ou aterros fossem, de fato, destinados à reciclagem, o país poderia lucrar cerca de $\mathrm{R} \$ 8$ bilhões.

O trabalho executado pelas cooperativas de reciclagem é tão expressivo que Ribeiro et al. (2014), ao estudarem as cooperativas do Rio de Janeiro, estimaram que estas são capazes de arrecadar anualmente cerca de $R \$ 34$ milhões. O Anuário da Reciclagem, desenvolvido entre os anos de 2017 e 2018 em parceria com a Pragma Soluções Sustentáveis estimou que as associações acompanhadas pela Associação Nacional dos Catadores e Catadoras de Materiais Recicláveis (ANCAT) arrecadaram cerca de $\mathrm{R} \$ 32$ milhões em 2018, o que equivale a 67 mil toneladas de resíduos coletados.

Desta forma, torna-se evidente o quanto o país perde economicamente por deixar de investir de forma adequada em coleta seletiva e reciclagem, e a necessidade em se aplicar uma gestão integrada mais eficiente, evitando que milhões sejam enterrados todos os anos em lixões e aterros sanitários (GRISA; CAPANEMA, 2018). 


\subsection{A QUESTÃO AMBIENTAL DA RECICLAGEM}

Por mais que os benefícios sociais e econômicos sejam evidentes, as cooperativas também prestam um papel ambiental notável. Ao reaproveitar materiais que seriam descartados (muitas vezes até em locais impróprios), reduz-se a necessidade de extração de matéria-prima, diminuindo, assim, a degradação ambiental advinda desta prática.

Ao realizar um estudo a partir do trabalho de 33 cooperativas da região metropolitana do Rio de Janeiro, com o intuito de estimar a influência da reciclagem na preservação de recursos naturais, Ribeiro et al. (2014) observaram que, só em 2008, o trabalho dessas cooperativas poupou 317 mil árvores, graças à reciclagem do papel; 1,6 mil toneladas de bauxita (reciclagem do alumínio); 2,5 mil toneladas de ferro; 59 mil barris de petróleo; e 342 toneladas de carvão mineral. Também foram poupados 77 mil MWh de energia elétrica e 1 milhão de metros cúbicos de água, o suficiente para suprir a necessidade de 24 mil pessoas no mesmo ano.

Além disso, a reciclagem ajuda a evitar o descarte de materiais que levariam muito tempo para se decompor, e ainda diminui o risco de contaminação de lençóis freáticos e do solo - o que muitas vezes ocorre em lixões, que são locais sem tratamento adequado do solo, pelo chorume decorrente da decomposição - preservando, assim, diversos hábitats e sua biodiversidade, além de trazer também benefícios à saúde humana, evitando a proliferação de vetores de doenças e a exposição da população a substâncias tóxicas, por exemplo (GOUVEIA, 2012; RODRIGUES; FEITOSA; SILVA, 2015).

Apesar desses impactos mais diretos, o descarte inadequado de resíduos também interfere no aumento dos níveis de Gases do Efeito Estufa (GEE), já que o processo de decomposição dos resíduos resulta principalmente na geração de metano $\left(\mathrm{CH}_{4}\right)$ e dióxido de carbono $\left(\mathrm{CO}_{2}\right)$, favorecendo, assim, as mudanças climáticas. Os resíduos contribuem com 2\% do total de emissões de GEE no Brasil. Entretanto, percebe-se um aumento da sua participação nessas emissões: crescimento de $77 \%$ entre 1990 e 2005 (GOUVEIA, 2012; RODRIGUES; FEITOSA; SILVA, 2015). 
Esse cenário evidencia que os efeitos da gestão inadequada dos resíduos sólidos têm uma repercussão que perpassa diferentes esferas e pode atingir toda a sociedade. Tal fato só reforça a importância de uma gestão integrada, com metas concretas a serem obtidas a partir da ação conjunta de diversos setores e que leve em consideração as particularidades locais, aspirando uma administração mais sustentável.

\section{CONSIDERAÇÕES FINAIS}

No período de dez anos analisado pelo trabalho (entre 2010 e 2020) observouse que o ano de 2015 se destacou por concentrar a maior parte das publicações, majoritariamente aquelas que trataram sobre a PNRS, devido ao período marcar os cinco anos desde sua aprovação. Outro fato importante foi a concentração dos trabalhos no eixo social, principalmente nos primeiros anos analisados, entre $2010 \mathrm{e}$ 2014. Apesar da existência de outros eixos de importância no debate da gestão dos resíduos sólidos, tal concentração no âmbito social pode ter ocorrido devido ao fato de este período em questão ter sido marcado pelo prosseguimento de políticas públicas de auxílios sociais e pela discussão do prazo final estipulado pela PNRS. Os municípios deveriam ter acesso a um local adequado para disposição dos resíduos sólidos, o que engloba a questão dos catadores, que por muito tempo trabalharam em lixões. Já a partir de 2016 foi possível observar a concentração de trabalhos que tratam sobre Gestão, Histórico e Definição, o que pode estar relacionado à baixa aderência dos mais diversos municípios brasileiros a uma gestão adequada dos resíduos nos últimos anos.

A pesquisa evidenciou que os avanços relacionados ao cumprimento das diretrizes estipuladas pela PNRS ainda estão muito aquém do esperado, inclusive em relação à reciclagem. Esta, por sua vez, ainda representa um potencial não explorado no Brasil. Entre as possíveis causas para essa situação, encontra-se a falta de programas amplos e integrados de gestão, em contraste com a forma isolada com que a reciclagem foi tratada até o momento pelo país. Além disso, esta atividade ainda é vista pelo poder público como algo inviável economicamente, desconsiderando o quanto o país poderia ganhar ao investir de forma adequada nesta área, além de ignorar também os benefícios sociais que este investimento poderia trazer à vida dos 


\section{¿Unisul}

catadores, assim como os ganhos ambientais, diminuindo a cada vez mais constante degradação ambiental oriunda da extração de matéria-prima - o que tem o potencial de impactar toda a sociedade.

Grande parte das publicações analisadas tratou sobre a questão social que permeia a gestão de resíduos sólidos, que é de extrema importância para a concretização de uma gestão efetiva. Reconhecer os principais atores que atuam na cadeia da reciclagem, investir nas cooperativas, incentivar a educação ambiental da população, além de fazer com que os poderes público e privado cumpram suas responsabilidades, fazendo valer as orientações da PNRS, são ações capazes de trazer inúmeros benefícios para o Brasil, o impulsionando para o caminho de uma gestão de resíduos sólidos mais integrada e sustentável. 


\section{REFERÊNCIAS}

ABRELPE - ASSOCIAÇÃO BRASILEIRA DE EMPRESAS DE LIMPEZA PÚBLICA E RESÍDUOS ESPECIAIS. Panorama dos Resíduos Sólidos 2010. Disponível em: <https://abrelpe.org.br/download-panorama-2010>. Acesso em: 24 jul. 2020.

ABRELPE - ASSOCIAÇÃO BRASILEIRA DE EMPRESAS DE LIMPEZA PÚBLICA E RESÍDUOS ESPECIAIS. Panorama dos Resíduos Sólidos 2018/2019. Disponível em: <https://abrelpe.org.br/download-panorama-2018-2019>. Acesso em: 24 jul. 2020.

ANCAT - ASSOCIAÇÃO NACIONAL DOS CATADORES E CATADORAS DE MATERIAIS RECICLẢVEIS. Anuário da Reciclagem 2017-2018. Disponível em: $<$ https://ancat.org.br/wp-content/uploads/2019/09/Anua\%CC\%81rio-da-

Reciclagem.pdf>. Acesso em: 24 jul. 2020.

ANDRADE, R. M.; FERREIRA, J. A. A Gestão de Resíduos Sólidos Urbanos no Brasil Frente às Questões da Globalização. REDE - Revista Eletrônica do PRODEMA, Fortaleza, v. 6, n. 1, mar. 2011.

BRASIL. Decreto Federal no 7.217, de 21 de junho de 2010. Regulamenta a Lei no 11.445, de 5 de janeiro de 2007, que estabelece diretrizes nacionais para o saneamento básico, e dá outras providências. Disponível em: <http://www.planalto.gov.br/ccivil_03/_ato2007-2010/2010/decreto/d7217.htm>.

Acesso em: 07 jul. 2020.

BRASIL. Lei no 12.305, de 2 de agosto de 2010. Institui a Política Nacional de Resíduos Sólidos; altera a Lei no 9.605, de 12 de fevereiro de 1998; e dá outras providências. Disponível em: <http://www.planalto.gov.br/ccivil_03/_ato20072010/2010/lei/l12305.htm>. Acesso em: 07 jul. 2020.

BOURAHLI, A. et al. A reciclagem como fator de inclusão socioeconômica dos catadores de lixo no Distrito Federal do Brasil. Revista Capital Científico, Guarapuava, v. 9, n. 2. p. 57-70, jul./dez. 2011.

CASTILHOS JUNIOR, A. B. et al. Catadores de materiais recicláveis: análise das condições de trabalho e infraestrutura operacional no Sul, Sudeste e Nordeste do Brasil. Ciência \& Saúde Coletiva, Rio de Janeiro, v. 18, n. 11, p. 3115-3124. 2013.

CELERI, M. J.; CORTEZ, A. T. C. Gestão dos Resíduos Sólidos Urbanos: o Brasil e Portugal em perspectiva. Revista Espacios, Caracas, v. 38, n. 21, p. 10-16. 2017.

CEMPRE - COMPROMISSO EMPRESARIAL PARA RECICLAGEM. Ciclosoft 2010. Disponível em: <http://cempre-org-br.umbler.net/wpcontent/uploads/2020/08/Ciclosoft-2010.pdf>. Acesso em: 23 jul. 2020. 
CEMPRE - COMPROMISSO EMPRESARIAL PARA RECICLAGEM. Ciclosoft 2018. Disponível em: <http://cempre-org-br.umbler.net/wpcontent/uploads/2020/08/Pesquisa-Ciclosoft-2018.pdf >. Acesso em: 24 jul. 2020.

DEUS, R. M.; BATTISTELLE, R. A. G.; SILVA, G. H. R. Resíduos Sólidos no Brasil: contexto, lacunas e tendências. Engenharia Sanitária e Ambiental, Rio de Janeiro, v. 20, n. 4, p. 685-698, out./dez. 2015.

ESTEVES, R. A. A Indústria do Resíduo: panorama das cooperativas de reciclagem e dos catadores de resíduos no estado do Rio de Janeiro. Revista Monografias Ambientais, Santa Maria, v. 14, n. 2, p. 86-99, mai./ago. 2015.

FERRAZ, L.; GOMES, M. H. A.; BUSATO, M. A. O Catador de Materiais Recicláveis: um agente ambiental. Cadernos EBAPE.BR, Rio de Janeiro, v. 10, n. 3, p. 763-768, set. 2012.

GARCIA, M. B. S. et al. Resíduos Sólidos: responsabilidade compartilhada. Semioses, Rio de Janeiro, v. 9, n. 2, p. 77-91, jul./dez. 2015.

GOUVEIA, N. Resíduos Sólidos Urbanos: impactos socioambientais e perspectiva de manejo sustentável com inclusão social. Ciência \& Saúde Coletiva, Rio de Janeiro, v. 17, n. 6, p. 1503-1510. 2012.

GRISA, D. C.; CAPANEMA, L. X. L. Resíduos sólidos Urbanos. In: PUGA, F. P.; CASTRO, L. B. (org.). Visão 2035: Brasil, país desenvolvido: agendas setoriais para alcance da meta. 1. ed. Rio de Janeiro: Banco Nacional de Desenvolvimento Econômico e Social, 2018, p. 415-438.

IBGE - INSTITUTO BRASILEIRO DE GEOGRAFIA E ESTATÍSTICA. Pesquisa Nacional de Saneamento Básico - 2008. Disponível em: $<$ https://biblioteca.ibge.gov.br/visualizacao/livros/liv45351.pdf>. Acesso em 30 jul. 2020.

IPEA - INSTITUTO DE PESQUISA ECONÔMICA APLICADA. Pesquisa sobre Pagamento por Serviços Ambientais Urbanos para Gestão de Resíduos Sólidos - 2010.2 Disponível em: <http://repositorio.ipea.gov.br/bitstream/11058/7968/1/RP_Pesquisa_2010.pdf>. Acesso em: 30 jul. 2020.

NASCIMENTO, V. F. et al. Evolução e desafios no gerenciamento dos resíduos sólidos urbanos no Brasil. Revista Ambiente \& Água, Taubaté, v. 10, n. 4, p. 889-902, oct./dec. 2015.

OLIVEIRA, C. B. A Questão Social da Reciclagem: um estudo sobre reflexividade, desigualdade e articulação de redes sociopolíticas no Rio Grande do Sul. 2010. 163 f. Dissertação (Mestrado em Ciências Sociais) - Faculdade de Filosofia e Ciências Humanas, Pontifícia Universidade Católica do Rio Grande do Sul, Porto Alegre, 2010. 
OLIVEIRA, T. B.; GALVÃO JUNIOR, A. C. Planejamento municipal na gestão dos resíduos sólidos urbanos e na organização da coleta seletiva. Eng. Sanit. Ambient., Rio de Janeiro, v. 21, n. 1, p. 55-64, jan./mar. 2016.

PIZZANI, L. et al. A arte da pesquisa bibliográfica na busca do conhecimento. RDBCl: Revista Digital de Biblioteconomia e Ciência da Informação, Campinas, v. 10, n. 1, p. 53-66, jul./dez. 2012.

PORTO, R. B. Comportamentos Relatados de Responsabilidade Ambiental, Social e Reciclagem: relação com gênero, idade e estratificação econômica. AOS Amazônia, Organizações e Sustentabilidade, Belém, v.1, n.1, p. 95-107, jan.jjun. 2012.

PUGLIESI, E.; SANTIAGO, C. D.; LEITE, W. C. A. Gestão de Resíduos Sólidos e a Pandemia COVID-19: (des)preparo para enfrentamento da crise. In: VALENCIO, N.; OLIVEIRA, C. M. (org.). COVID-19: Crises entremeadas no contexto de pandemia (antecedentes, cenários e recomendações). São Carlos: UFSCar/CPOI, 2020. cap. 9 , p. $135-150$.

REIS, A. C. M.; PONTES, A. N. Resíduos Sólidos Urbanos no Brasil: A Reciclagem no Contexto da Sustentabilidade. Revista Observatorio de la Economía Latinoamericana, Pará, v.1, p. 1-12, nov. 2019.

RIBEIRO, L. C. S. et al. Aspectos econômicos e ambientais da reciclagem: um estudo exploratório nas cooperativas de catadores de material reciclável do Estado do Rio de Janeiro. Nova Economia: Estante de Economia e Sociedades Brasileira. Belo Horizonte, v. 24, n. 1, p. 191-214, jan./abr. 2014.

RODRIGUES, G. L.; FEITOSA, M. J. S.; SILVA, G. F. L. Cooperativas de Reciclagem de Resíduos Sólidos e seus Benefícios Socioambientais: um estudo na COOPECAMAREST em Serra Talhada - PE. Revista Metropolitana de Sustentabilidade, São Paulo, v. 5, n. 1, p. 19-38, jan./abr. 2015.

SILVA, C. L.; FUGII, G. M.; MARINI, M. J. Gestão da Cadeia de Reciclagem em Rede: um estudo do projeto Ecocidadão no Município de Curitiba. Desenvolvimento Regional em debate, Santa Catarina, v. 5, n. 1, p. 20-37, jan./jun. 2015.

SILVA, K. C.; ROSAS, L. S. P.; OLIVEIRA, S. R. N. Gestão dos Resíduos Sólidos do Brasil: evolução e desafios a caminho - uma revisão integrativa. Scientia Amazonia, Manaus, v. 7, n. 2, p. CA1-CA15, 2018.

SILVA, S. P. Reciclagem e Economia Solidária: análise das dimensões estruturais dos empreendimentos coletivos de catadores no Brasil. Revista de Ciências Sociais - Política \& Trabalho, João Pessoa, n. 46, p. 229-249, jan./jun.2017.

SILVEIRA, D. C.; SOUSA, F. F.; TEIXEIRA, C. Relevância Socioambiental da Coleta Seletiva no Município de Itaúna: visão de catadores e da comunidade. Fronteiras: Journal of Social, Technological and Environmental Science, Anápolis, v. 8, n. 1, p. 301318, jan./abr. 2019. 
SNIS - SISTEMA NACIONAL DE INFORMAÇÕES SOBRE SANEAMENTO. Diagnóstico do Manejo de Resíduos Sólidos Urbanos - 2010. Disponível em: <http://www.snis.gov.br/diagnostico-anual-residuos-solidos/diagnostico-rs-2010>. Acesso em: 24 jul. 2020.

SNIS - SISTEMA NACIONAL DE INFORMAÇÕES SOBRE SANEAMENTO. Diagnóstico do Manejo de Resíduos Sólidos Urbanos - 2018. Disponível em: $<$ http://www.snis.gov.br/diagnostico-anual-residuos-solidos/diagnostico-do-manejo-deresiduos-solidos-urbanos-2018>. Acesso em: 24 jul. 2020.

SOUZA, A. R. D.; MELO, C. S. Logística reversa: um estudo sobre o processo de coleta de baterias em um distribuidor na cidade de Porto Velho-RO. Diálogos: Economia e Sociedade, Porto Velho, v.2, n.2, p. 110-120, jul./dez. 2018.

SOUZA, O. T.; CHAVES, I. R.; ALVIM, A. M. Reciclagem e gestão de resíduos sólidos como possibilidades para a geração de benefícios sociais, econômicos e ambientais. Revista Grifos, Rio Grande do Sul, v. 24, ed. 38/39, p. 51-70, 2015.

THODE FILHO, S. et al. A Logística Reversa e a Política Nacional de Resíduos Sólidos: Desafios Para a Realidade Brasileira. Revista Eletrônica em Gestão, Educação e Tecnologia Ambiental, Rio de Janeiro, v. 19, n. 3, p. 529-538, set./dez. 2015.

United Nations. The Sustainable Development Goals Report 2020. Disponível em: $<$ https://unstats.un.org/sdgs/report/2020/The-Sustainable-Development-Goals-Report2020.pdf>. Acesso em: 29 jul. 2020.

VERGARA, S. C.; PECI, A. Escolhas metodológicas em estudos organizacionais. Organizações \& Sociedade, v. 10, n. 27, p. 13-26, mai./ago. 2003.

WIRTH, I. G. As relações de gênero em cooperativas populares do segmento da reciclagem = um caminho para a construção da autogestão?. 2010. 226 p. Dissertação (Mestrado em Educação) - Faculdade de Educação, Universidade Estadual de Campinas, Campinas, 2010. 